\title{
Comprehensive improvement of energy efficiency and environmental friendliness of a solid fuel boiler house
}

\author{
Roman Kondratev* \\ Nizhny Novgorod State University of Architecture and Civil Engineering, 603000, Nizhny Novgorod, \\ Russia
}

\begin{abstract}
Measures to improve the energy efficiency of boiler houses must be carried out in a complex, taking into account the interconnection of all obtaining heat energyprocesses, their automation and greening. A number of experiments have been carried out on UHFheating, drying and subsequent ignition of various types of solid fuels. Duration determinedUHF-impact and distribution of temperatures on the fuelsurface, depending on its moisture content and fraction. It is proposed to use a precombustion device to increase the energy characteristics of fuel with a high moisture content (up to $80 \%$ ) by combined heating of an electromagnetic fieldUHFand convective thermal - flue gases, as well as a condensing air heater. The results of the pre-combustion device usefor combined heating are: an increase in the drying solid fuelefficiency, an increase in its combustionheat. Homogenized fuel was obtained from low-grade cheap solid fuel with a high moisture content (wood waste), which in its energy characteristics is not inferior to expensive pellets. The joint work of the developed pre-furnace design and the condensing air heater allows: to determine the efficiency factor of a boiler plant, reduce fuel consumption, involve wood waste and low-calorie fuel with a high moisture content (up to 80\%) in the fuel balance of boiler houses, recycle and reuse the heat of flue gases, reduce the concentration of corrosive substances in flue gases and condensate, which allows use it as make-up and process water.
\end{abstract}

\section{Introduction}

Energy saving is one of the main trends in the development of heat and power engineering in the world. One of the ways to solve the energy saving problem when obtaining heat energy in boiler plants using solid fuels is to increase their energy efficiency by improving fuel supply systems and fuel preparation for combustion, utilization and recycling heat from

\footnotetext{
*Corresponding author: rvkondratev@mail.ru
} 
flue gases, condensate, fuel saving and an increase in the use of low-calorie fuel (low-grade coal, peat with a high (up to 80\%) moisture content) and secondary energy resources wood waste (hereinafter WW)[1]. At the same time, the consideration and detailed study of the above-listed measures to improve the energy efficiency of boiler houses must be carried out in a complex, taking into account the interrelation of all processes of obtaining heat energy, their automation and greening.

\section{Materials and Methods}

For a comprehensive solution of the above-mentioned tasks related to improving the energy efficiency and environmental friendliness of a solid fuel boiler plant, it is proposed to use an automated fuel supply system [2], in which, upon the boilerdelivery, the fuel quality is monitored and prepared for combustion. It includes a pre-combustion device for increasing the energy characteristics of fuel with high humidity (up to $80 \%$ ) by combined heating by an UHFelectromagnetic field [3] and convective thermal - flue gases, as well as heat exchange equipment - condensing air heater (hereinafter $\mathrm{CAH}$ ).

Figure 1 shows a diagram of a pre-combustion device for combined heating (UHF + flue gases) to prepare for solid fuel combustion [4].


Fig. 1.Scheme of a pre-combustion device for combined heating: 1 - loading chamber; 2 - UHF generator; 3 - gas duct; 4 - smoke exhauster; 5 - drive mechanism; 6 - moisture meter; 7 - temperature sensor; 8 - flue gas cleaning device; 9 - fuel line; 10 - unloading hopper (hopper of dry material); 11 upper flaps; 12 - metering auger; 13 - lower flaps; 14 - loading sensor; 15 - supply chimneygate; 16 gas duct (bypass line).

Figure 2 shows a diagram of the gas and air paths of the boiler plant (hereinafter BP)with solid fuel boilerKVT-200 [5], a pre-combustion device for combined heating and $\mathrm{CAH}$. 




Fig. 2. Gas and air circuit BPdiagram with pre-combustion device for combined heating and condensing air heater: K1 - hot water boiler KVT-200; K2 - battery cyclone (BC); K3 - shell and tube air heater; $\mathrm{K} 4$ - condensate collection tank; K5 - blower fan; K6 - smoke exhauster; K7 chimney steel; K8 - combined heating pre-combustion device; $\mathrm{F}$ - boiler furnace, HE - heat exchanger; 0 - entrance to the furnace (entrance to the boiler); 1 - exit from the boiler (entrance to the cyclone); 2 - exit from BC (entrance to the pre-furnace combined heating device); 3 - outlet from the pre-furnace combined heating device (inlet to the air heater); 4 - outlet from the air heater (inlet to the gas duct); 5 - entrance to the chimney (exit from the flue).

Before designing the pre-furnace device, a number of experiments were carried out on UHFheating, drying and subsequent ignition of solid fuels of various types [6]. The following was determined: UHF- impactduration, the field of temperature distribution on the fuelsurface, depending on its moisture content and fraction. The temperature of the fuelsouter surface was determined by a non-contact method using a high-precision thermal imager. Figure 3 shows a thermogram of the temperature field distribution on the WW sample surface under the UHF - radiation influence[7, 8], in Figure 4 - on the surface of a peat sample.



Fig. 3.Distribution of the temperature field in the WWsample under the UHF - radiationinfluence 


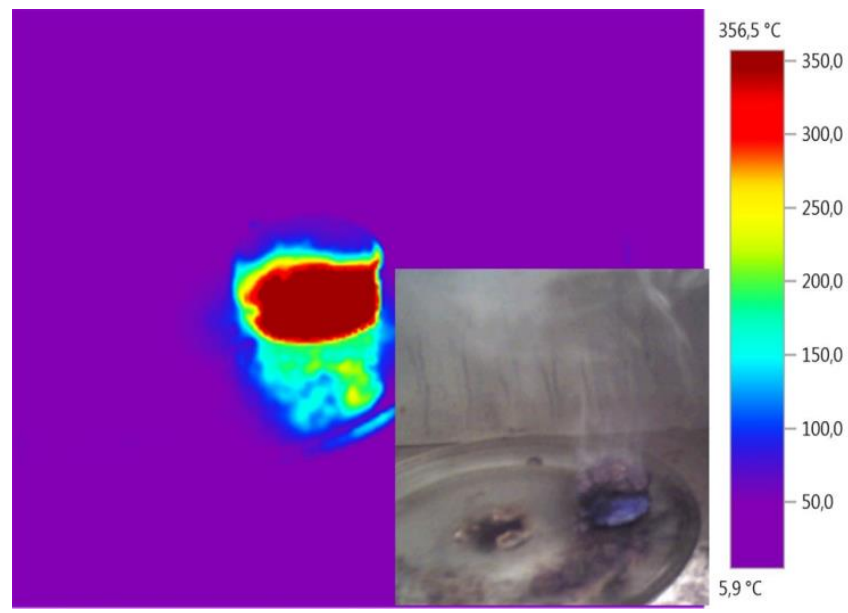

Fig. 4. Distribution of the temperature field in a peat sample under the UHF - radiationaction

The experiments are described in [6].

\section{Results and Discussions}

The results of experimental studies of the UHF electromagnetic field effect for various samples of wood fuel and peat with a high moisture content, given in Tables 1, 2 and Figure 5, showed: the fuel drying process is sharply intensified, which is accompanied by the formation and opening of new internal and external cracks, pores and capillaries; the surface layer destruction of the samples (peat, coal) occurs; the elemental composition of the fuel changes: the content of nitrogen $(\mathrm{N})$ is decreased significantly (up to $30 \%$ ), the content of hydrogen $(\mathrm{H})$ is decreased to $3 \%$; the heat of combustion is increased: from 10.22 to $16,76 \mathrm{MJ} / \mathrm{kg}$ - wood fuel, peat - from 8,5 to $17,29 \mathrm{MJ} / \mathrm{kg}$; upon reaching the required temperature and moisture content, the sample ignites. Thus, as a result, a homogenized fuel was obtained from low-grade cheap solid fuel with a high moisture content, which in its energy characteristics is not inferior to expensive pellets (fuel pellets).

Table 1. Field UHFimpact results for wood fuel samples

\begin{tabular}{|c|c|c|c|c|c|}
\hline No. & Fueltype & $\begin{array}{c}\text { Fuelmo- } \\
\text { isture, } \%\end{array}$ & $\begin{array}{c}\text { Fractionsiz } \\
\mathrm{e}, \mathrm{cm}\end{array}$ & $\begin{array}{c}\text { Time to the } \\
\text { sampleignition, } \\
\text { sec }\end{array}$ & $\begin{array}{c}\text { Sampleigni } \\
\text { tiontemper } \\
\text { ature, }{ }^{0} \mathrm{C}\end{array}$ \\
\hline 1 & $\begin{array}{c}\text { Beech } \\
\text { (woodchips) }\end{array}$ & 48.6 & $3-5$ & 323 & 296.9 \\
\hline 2 & Pellets & 11 & $1 \times 5$ & 222 & 324 \\
\hline 3 & Pellets & 15 & $1 \times 5$ & 187 & 324 \\
\hline 4 & Pellets & 39.6 & $1 \times 5$ & 211 & 324 \\
\hline 5 & $\begin{array}{c}\text { Aspen } \\
\text { (woodchips) }\end{array}$ & 30.0 & $3-6$ & 268 & 282 \\
\hline 6 & Cork & 45.7 & $5-8$ & 186 & 266 \\
\hline 7 & Spruce & 43.8 & $7-10$ & 146 & 289 \\
\hline 8 & Spruce & 70 & $7-10$ & 259 & 289 \\
\hline 9 & Spruce & 91 & $7-10$ & 342 & 289 \\
\hline 10 & Sawdust & 45 & 1 lessthan 1 & 479 & 272 \\
\hline
\end{tabular}


Table 2. Results of periodic and continuous field exposureUHFfor wood fuel samples

\begin{tabular}{|c|c|c|c|c|c|}
\hline No. & Fuel type & $\begin{array}{c}\text { Fuel } \\
\text { mo- } \\
\text { isture, } \%\end{array}$ & $\begin{array}{c}\text { Fraction } \\
\text { size, cm }\end{array}$ & $\begin{array}{c}\text { Sample ignition } \\
\text { time with } \\
\text { continuous } \\
\text { UHFexposurera- } \\
\text { diation, sec }\end{array}$ & $\begin{array}{c}\text { Sample ignition } \\
\text { time with periodic } \\
\text { UHFexposure } \\
\text { radiation (with a } \\
\text { period of } 40 \\
\text { seconds), sec }\end{array}$ \\
\hline 1 & Spruce & 43,8 & $7-10$ & 146 & 228 \\
\hline 2 & $\begin{array}{c}\text { Aspen } \\
\text { (woodchips } \\
\text { ) }\end{array}$ & 30,0 & $3-6$ & 268 & 349 \\
\hline
\end{tabular}

The technical result from the use of the proposed pre-furnace combined heating device consists in increasing the efficiency of drying the dielectric material due to combined heating by an electromagnetic field UHFwith the wave length $0,1224 \mathrm{~m}$, frequency 2,45 $\mathrm{GHz}[9,10]$ and flue gases, temperature $150-250{ }^{\circ} \mathrm{C}$.

During the operation of the pre-furnace combined heating device, the following processes are carried out [11 - 14]:

1. Fuelpre-heating;

2. Dehydration (water removal) with cracking;

3. Drying of large pieces (up to $125 \mathrm{~mm}$ );

4. Maintaining the required fuel temperature before unloading it into the boiler unit (hereinafter BU);

5. Additional grinding (peat, coal) at UHF- heating.

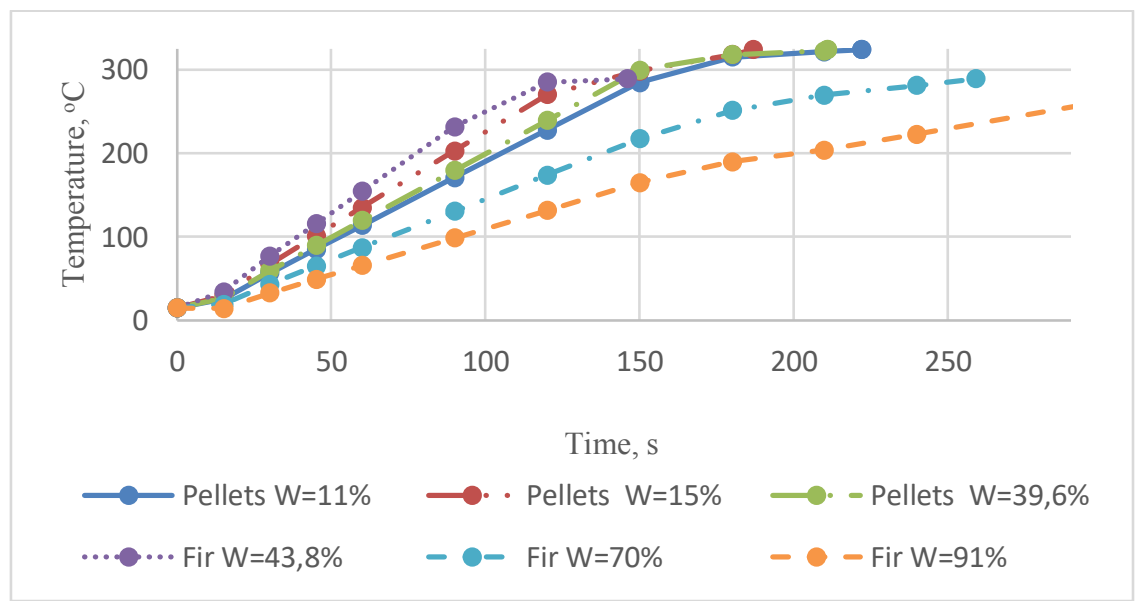

Fig. 5.The graph of the temperature distribution on the surface of the samples under the UHF radiationaction

The combined heating method gives the maximum positive result of increasing the solid fuel energy characteristics and, as a result, increases BPenergy efficiency (efficiency factor) when used simultaneously withUHF - radiation, convection and heat of flue gases. The data are shown in Table 3.

Practical use of the developed pre-furnace design allows to increase BP efficiency factor, increase the degree of automation of the entire cycle of obtaining thermal energy, 
balance the BUtemperature regimein case of batch loading of fuel by ensuring stable combustion of fuel and improving the quality of transient processes in dynamic modes during its loading, to increase the reliability degree of the boiler plants in automatic mode, to abandon the construction and operation of drying warehouses, to use low-grade fuel with a high moisture content (up to $80 \%$ ) (waste from logging and woodworking, peat, etc. to be disposed of), reduce mechanical, chemical under-burning of fuel and the amount of harmful emissions released into the atmosphere with flue gases.

Joint use of the developed pre-furnace design of combined heating andCAHgives an opportunity to increase BP efficiency factor, utilize and reuse the heat of flue gases, dry and cool them before emitting into the atmosphere, reduce the concentration of corrosive substances in flue gases and condensate, which allows it to be used as make-up and process water.

Application of UHFfield influence for solid fuel in the BUfurnace provides automatic ignition of solid fuel without the use of flammable substances.

Table 3. The results of the boiler plant operation with various configurations on wood waste (WW)

\begin{tabular}{|c|c|c|c|c|}
\hline Indicator name & $\mathrm{W}=40 \%$ & $\begin{array}{l}\mathrm{W}=40 \% \\
\mathrm{CAH}\end{array}$ & $\begin{array}{l}\mathrm{W}=10 \% \text { pre- } \\
\text { furnace device }\end{array}$ & $\begin{array}{c}\mathrm{W}=10 \% \\
\text { with } \\
\text { column } 3 \\
+ \text { column } \\
4\end{array}$ \\
\hline 1 & 2 & 3 & 4 & 5 \\
\hline $\begin{array}{l}\text { Lower calorific fuelvalue, } \\
\mathrm{MJ} / \mathrm{kg}\end{array}$ & 10,216 & 10,216 & 16,758 & 16,758 \\
\hline Fuel consumption BP, kg/h & 264,299 & 264,299 & 161,117 & 161,117 \\
\hline $\begin{array}{l}\text { Combustion products } \\
\text { temperature downstream of } \\
\text { the boiler or CAHif } \\
\text { available, }{ }^{0} \mathrm{C}\end{array}$ & 240,000 & 45,000 & 45,000 & 45,000 \\
\hline $\begin{array}{l}\text { Excess air ratio after the } \\
\text { boiler or CAHif available }\end{array}$ & 1,400 & 1,500 & 1,500 & 1,600 \\
\hline Flue gas volume, $\mathrm{m}^{3} / \mathrm{s}$ & 0,935 & 0,616 & 0,376 & 0,398 \\
\hline $\begin{array}{c}\text { Heat loss with flue gases } \mathrm{q}_{2} \text {, } \\
\%\end{array}$ & 15,275 & 8,130 & 10,765 & 3,754 \\
\hline $\begin{array}{l}\text { Heat loss from chemical } \\
\text { under-burning } \mathrm{q}_{3}, \%\end{array}$ & 2,000 & 2,000 & 1,500 & 1,500 \\
\hline $\begin{array}{c}\text { Heat loss of } \\
\text { mechanicalunder-burning } \mathrm{q}_{4}, \\
\%\end{array}$ & 2,000 & 2,000 & 1,500 & 1,500 \\
\hline $\begin{array}{l}\text { Heat loss to the environment } \\
\mathrm{q}_{5}, \%\end{array}$ & 4,000 & 4,000 & 4,000 & 4,000 \\
\hline $\begin{array}{l}\text { Efficiency factor boiler } \\
\text { gross, } \%\end{array}$ & 76,725 & 83,87 & 82,235 & 89,580 \\
\hline
\end{tabular}

\section{Conclusion}

Practical application of technical solutions and structures with an integrated approach to solving the problems related to improving energy efficiency and BPenvironmental friendliness on solid fuel gives an opportunity: 
1) to upgradeBP efficiency factor;

2) to increase the technical and economic indicators of BPheat production;

3 ) to increase the reliability degree of the installations in automatic mode;

4) to reducefuelconsumption;

5) to use as fuel waste from logging and woodworking, low-grade types of peat and coal with high humidity (up to $80 \%$ );

6) to recycle and reuse the heat of flue gases, to reduce the concentration of corrosive substances in flue gases and condensate, which makes it possible to use it as make-up and process water;

7) reduce the amount of harmful emissions emitted into the atmosphere with flue gases.

The developed pre-furnace design of combined heating and CAHcan be implemented on the commercially available equipmentbasis.

These technologies can be used both in the design of new and in the modernization of the existing heat generating facilities.

\section{References}

1. S.I. Golovkov, I.F. Koperin, V.I. Naydenov Energy use of wood waste (M., Lesn. prom-th. 1987).

2. Fuel supply [Electronic resource]. URL:https://kotel-kv.kz/toplivopodacha.html (Date of the application: 18.05.2021)

3. V.P. Galkin, I.I. Postnikov, Materials of the All-Union Scientific and Technical Conference. Arkhangelsk (1990)

4. R.V. Kondratyev, Privolzhsky scientific journal 3 (47), 50-56. (2018).

5. Kovrov boilers [Electronic resource]. URL: http://www.termowood.ru/boilers.html (Date of the application: 18.05.2021)

6. R.V. Kondratyev, M.A. Kocheva, Privolzhsky scientific journal 1 (49), 70-76 (2019).

7. A. N. Kachanov, D.A. Korenkov, To lead the higher educational institutions of the Chernozem region 1 (47), 16-26 (2017).

8. A. N. Kachanov, D.A. Korenkov, KrasSAU Bulletin 9 (120), 113-121 (2016).

9. D. Boldor, T.Sanders, K. Swartzel, B. Farkas, J. of Food Process Engineering. 28, 6887 (2005).

10. M. Hossan, P. Dutta, International Journal of Heat and Mass Transfer 55, 3412-3422 (2012).

11. A. Antti, H. Zhao, I. Turner, Theory and practice. Drying Technology 18(8), 16651676 (2000).

12. A. Dedic, M. Zlatanovic, HolzalsRoh und Werkstoff 59, 246-249 (2001).

13. D.Guanben, W. Sigun, C. Zhiyong, UHF Drying of Wood Strands. Drying Technology 23, 1-16 (2005).

14. W. James, D. Hamill, Forest pro duct journal 15 (2), 51-56 (1965). 